\title{
Erratum to: Antiviral activity of Bifidobacterium adolescentis SPM 0214 against Herpes Simplex Virus Type 1
}

Hyang Mi An • Do Kyung Lee · Jung Rae Kim •

Si Won Lee $\cdot$ Min Kyeong Cha $\cdot$ Kang Oh Lee $\cdot$

Nam Joo Ha

Published online: 6 November 2014

(c) The Pharmaceutical Society of Korea 2014

Erratum to: Arch Pharm Res (2012) 35(9):1665-1671

DOI 10.1007/s12272-012-0918-9

In this article, unfortunately some errors were made by the authors. Acknowledgement should appear as shown below:
This research was supported by the Sahmyook University Research Fund (2012).

The online version of the original article can be found under doi:10.1007/s12272-012-0918-9.

H. M. An · D. K. Lee $\cdot$ J. R. Kim - S. W. Lee

M. K. Cha $\cdot$ N. J. Ha $(\bowtie)$

Department of Pharmacy, Sahmyook University, Seoul 139-742,

Korea

e-mail: hanj@syu.ac.kr

K. O. Lee

Department of Life Science, Sahmyook University,

Seoul 139-742, Korea 